\title{
Tratamentos jurídicos: os mercados terapêuticos e a judicialização do direito à saúde*
}

\author{
Legal remedies: therapeutic markets and the \\ judicialization of the right to health
}

\section{João Biehl}

Professor, Cátedra Susan Dod Brown/Department of Anthropology/Princeton University. 128 Aaron Burr Hall 08544 - Princeton - NJ - EUA jbiehl@princeton.edu

\section{Adriana Petryna}

Professor, Cátedra Edmund J. and Louise W. Kahn/Department of Anthropology/University of Pennsylvania School of Arts and Sciences.

3260 South Street

19104-6398 - Philadelphia - PA

- EUA

petryna@sas.upenn.edu
BIEHL, João; PETRYNA, Adriana. Tratamentos jurídicos: os mercados terapêuticos e a judicialização do direito à saúde. História, Ciências, SaúdeManguinhos, Rio de Janeiro, v.23, n.1, jan.-mar. 2016, p.173-192.

\section{Resumo}

Esse estudo mostra a luta de pais para que filhos portadores de mucopolissacaridose tenham acesso a medicamentos caros, em nome do direito universal à saúde. $\mathrm{O}$ trabalho explora como, no Brasil, o litígio pelo direito à saúde tornou-se um caminho alternativo de acesso à saúde e evidencia a disputa de diferentes atores dos setores público e privado no processo de judicialização da saúde. Entende-se, portanto, que a biotecnologia recria valores humanos e mundos locais à medida que abre novos espaços de problematização ética, desejo e pertencimento político.

Palavras-chave: farmaceuticalização da saúde; judicialização da saúde; biotecnologia; Brasil.

\section{Abstract}

This study draw on the struggle of parents of children with mucopolysacchar idosis to access expensive drugs in the name of universal right to health. The work explores how, in Brazil, right-to-health litigation became an alternative pathway to access health care and shows that several public and private stakeholders dispute the judicialization of health. Biotechnology is, therefore, understood to remake human and social worlds as it opens up new spaces of ethical problematization, desire, and political belonging.

Keywords: pharmaceuticalization of health; judicialization of health; biotechnology; Brazil. 


\begin{abstract}
Não existe justiça! Não existem direitos humanos. O que importa é a jurisprudência. Esta é a invenção da lei... O desafio é criar os direitos humanos, e não só torná-los aplicáveis. É uma questão de inventar jurisprudências para que, em cada caso, tal e tal coisa não houvesse sido possível... Muitas vezes, podemos ver a vida caso a caso... Não se trata de um direito disso ou daquilo, mas de situações que evoluem... de lutar por jurisprudência... para criar o direito.
\end{abstract}

Gilles Deleuze $^{1}$

\title{
Entrando na Justiça, caso a caso
}

Sete crianças em um quarto de hospital recebendo medicação intravenosa. ${ }^{2}$ Seus pais não saem de perto, batendo papo entre si e com os médicos que entram e saem. Toda semana esses pais trazem seus filhos, que sofrem de uma doença chamada mucopolissacaridose (MPS), à Unidade de Pesquisa do Hospital Universitário, um hospital de ensino público de Porto Alegre, capital do Rio Grande do Sul. ${ }^{3}$ Elas estão recebendo a terapia de reposição enzimática, que pode custar até duzentos mil dólares por ano por paciente. ${ }^{4}$

A MPS engloba um grupo de distúrbios metabólicos herdados em que mucopolissacarídeo, um carboidrato complexo, desenvolve-se em tecidos do corpo de forma não metabolizada e perigosa devido à falta de atividade de uma enzima específica (Beck, 2007). Estima-se que uma em cada 25 mil pessoas sofra de distúrbios de MPS (Clarke, 2008), e isso costuma se manifestar na infância. Esses distúrbios se caracterizam por deformidades no esqueleto e nas juntas, crescimento atrofiado e mudanças faciais causadas pelo acúmulo de mucopolissacarídeos no osso de sustentação facial. A MPS ocasiona deficiências neurológicas, cardiovasculares e respiratórias, aumento do fígado e do baço e perda de audição. Os casos mais graves são fatais nos primeiros dez anos de vida. Os casos moderados podem implicar um tempo de vida normal, embora com taxa de morbidade relativamente alta (Clarke, 21 set. 2007). Não existe cura para os distúrbios de MPS, mas as terapias de reposição enzimática têm-se mostrado eficazes na redução de alguns sintomas, melhorando a qualidade de vida e, em alguns casos, prolongando o tempo de vida.

Todas as crianças com MPS que se encontram nesse quarto são pacientes litigantes. Seus pais estão processando o governo para que recebam tratamento pelo resto da vida. Entre 2008 e 2011, conversamos com diversos atores envolvidos nessa prática nova e cada vez mais onipresente de ações judiciais contra o Estado para ter acesso a tratamentos médicos, um fenômeno conhecido como a "judicialização do direito à saúde". Apesar de os pacientes processarem todas as esferas do governo por diferentes motivos, desde uma fórmula para bebês até cirurgias complexas, parcela significativa das ações judiciais é movida para obter medicamentos.

O Brasil é um dos cerca de cem países que reconhecem o direito constitucional à saúde (Gauri, Brinks, 2008, p.1). Uma parte importante desse direito é o acesso a medicamentos. Embora o Brasil tenha um dos programas mais avançados do mundo de tratamento do HIV/ Aids, por exemplo, muitos cidadãos ainda não encontram medicamentos essenciais disponíveis nas farmácias locais. Com cerca de duzentos milhões de habitantes e uma economia em 
ebulição, o Brasil, hoje, é um dos mercados farmacêuticos com maior taxa de crescimento no mundo. É cada vez maior o número de prescrições médicas e a demanda de pacientes por novas tecnologias médicas.

A Food and Drug Administration (FDA) norte-americana e a Agência Nacional de Vigilância Sanitária (Anvisa) no Brasil aprovaram alguns tratamentos de MPS; outros ainda estão em fase de ensaios clínicos. ${ }^{5}$ Empresas de biotecnologia estão entrando no campo de tratamentos de doenças órfãs, apresentando novidades em relação ao defasado modelo de desenvolvimento de medicamentos das últimas décadas (Petryna, 2009). ${ }^{6}$

Médicos do Hospital Universitário estavam empolgados com a possibilidade de finalmente oferecer aos pacientes algo além de apenas um diagnóstico preciso de sua afecção genética. Mas também se mostravam cautelosos com as expectativas exageradas de eficácia. Segundo a doutora Maria, que monitora essas crianças, "este é um mundo novo. Acredito que trouxemos algo novo da genética para o SUS [Sistema Unificado de Saúde]. Alguns destes pacientes passaram por ensaios clínicos, mas todos são pacientes do SUS agora. É bem problemático garantir o acesso ao tratamento e acompanhar sua eficácia". Os interesses da pesquisa clínica, a saúde pública e os mercados biomédicos passam a se integrar aos corpos desses jovens pacientes-cidadãos-litigantes.

As crianças aqui são de famílias de classe média e baixa que jamais teriam recursos financeiros para pagar por essas terapias genéticas. Elas conseguem isso graças às ações judiciais que seus pais abrem contra o estado do Rio Grande do Sul, em nome do direito à saúde. O artigo 196 da Constituição de 1988 afirma que a saúde é direito de todos e dever do Estado, "garantido mediante políticas sociais e econômicas que visem à redução do risco de doença e de outros agravos e ao acesso universal igualitário a ações e serviços" (Brasil, 1988). Os pais nos contaram que, para fazer tal pedido, precisam ter um diagnóstico e documentos médicos que comprovem os reais benefícios de um tratamento tão caro. $\mathrm{Na}$ maioria dos casos, juízes distritais emitem logo injunções que forçam o estado a oferecer o tratamento por um ou dois meses. O acórdão final por instâncias superiores pode levar anos, porque os promotores públicos apresentam vários recursos, os comitês especializados analisam evidências médicas, e o caso pode ainda tomar um rumo menos linear e chegar ao Supremo Tribunal Federal, em Brasília.

O fabricante do medicamento paga algumas infusões de apenas uma das sete crianças. Rita, que tem 12 anos de idade e se encontra "em um estado quase vegetativo" (segundo sua mãe, Ilse), fez parte dos primeiros ensaios clínicos que levaram à aprovação do medicamento no Brasil. Em 2004, quando os ensaios foram concluídos e o patrocinador dos testes parou de fornecer a enzima com base no uso compassivo, Rita tornou-se uma das primeiras pacienteslitigantes da MPS no estado. Ela ganhou uma liminar judicial inicial que precisava ser renovada periodicamente, pois os promotores públicos contestavam a sentença. Um médico disse que, nesse ínterim, o fabricante concordou em compartilhar o custo do tratamento da Rita com o estado, muito provavelmente para evitar se tornar um réu no Supremo Tribunal. Para todas essas crianças, a história natural incerta e talvez fatal de sua doença agora se articula com as esperançosas terapias genéticas de ponta, e com um processo judicial demorado. A questão essencial de quem pagará pela terapia - a família, o governo ou o fabricante - está associada ao campo emergente da jurisprudência sobre o direito ao tratamento. 
A infusão que leva três horas acabou, e as crianças estão acordadas, conversando e brincando - todas com exceção de Rita. Ilse faz carinho no rosto da filha. Assim como todas as crianças com MPS naquele quarto de hospital, Rita tem baixa estatura e crânio aumentado. Apresenta desproporção crânio-facial e o esqueleto deformado. Segundo Ilse, a filha apresenta um "atraso" no desenvolvimento mental. Ao pé da cama de Rita, encontra-se uma pasta vermelha contendo os registros médicos mais recentes e as decisões judiciais. "Ao final do ensaio clínico, contatamos um advogado particular, o doutor Moura, e entramos na Justiça contra o Estado para obter a enzima. Outros pais fizeram o mesmo", conta Ilse, "a Rita é uma cidadã. Aqui no Brasil, ela tem o direito à saúde". Ilse, bem como os demais pais na sala de infusão, usa a expressão "entrar na Justiça" (que significa "mover uma ação na Justiça") para se referir às ações judiciais.

No Brasil inteiro, pacientes recorrem à Justiça para ter acesso a medicamentos prescritos (Azevedo, 20 dez. 2007; Colluci, 9 jan. 2009). Embora as ações judiciais garantam o acesso a milhares de pessoas, pelo menos temporariamente, essa judicialização do direito à saúde gera realidades sociomédicas extremamente complexas (conforme exemplificado pelas famílias com MPS), além de enormes desafios administrativos e fiscais que, segundo especialistas, têm o potencial de aumentar as desigualdades na prestação de serviços de saúde (Ferraz, 2009). Neste ensaio, exploramos como o litígio pelo direito à saúde tornou-se (no rastro de uma política bem-sucedida de tratamento da Aids) uma rota alternativa para brasileiros terem acesso aos serviços de saúde, agora compreendido como o acesso a medicamentos que estão nas listas governamentais ou só são disponibilizados no mercado. O sistema judiciário é um local efetivo para a implementação dos direitos socioeconômicos? Que práticas de cidadania e governança são cristalizadas nessa luta pelo acesso a medicamentos e pela responsabilidade administrativa?

Os medicamentos comprados pelo governo representam um mercado descomunal no Brasil, e, como veremos, o litígio pelo tratamento ocorre no contexto de um sistema descentralizado e disfuncional de saúde pública. Também não se deve negligenciar a função das forças de mercado na judicialização - uma mistura de estratégias de marketing farmacêutico que visam a prescrições médicas e aquecem a demanda de pacientes, bem como a supervisão regulatória limitada. Mas um fator-chave aqui é que pacientes de baixa renda não estão simplesmente aguardando que o mercado eventualmente baixe os preços e torne as novas tecnologias médicas acessíveis: eles estão usando a assistência jurídica pública e as alavancas de um Judiciário responsivo para obter acesso agora.

O fenômeno conjunto da "farmaceuticalização" do cuidado e da "judicialização" dos direitos socioeconômicos levanta questões cruciais que estão no cerne dos debates atuais sobre saúde no mundo inteiro: o acesso à tecnologia e a prestação de serviços de saúde, o financiamento e a sustentabilidade de programas de tratamento, o fortalecimento de sistemas de saúde e a melhoria dos resultados. Precisamos de uma compreensão mais profunda de como a economia política dos fármacos informa as iniciativas de tratamento em grande escala. Também precisamos saber como a informação, a ciência e a tecnologia afetam os sistemas de saúde e os projetos de vida na prática. 


\section{A farmaceuticalização e a judicialização}

A adoção pelo Brasil de um direito constitucional à saúde, em 1988, foi acompanhada da criação do Sistema Único de Saúde (SUS), estendendo a cobertura de saúde a todos os cidadãos. Para melhorar o gerenciamento do sistema público de saúde, o Ministério da Saúde dividiu as responsabilidades de distribuição farmacêutica entre três níveis de governo, como parte de um processo mais amplo de descentralização. Enquanto o governo federal manteve parte de sua função central de financiamento da saúde pública (administrando programas voltados para doenças de alta prioridade que exigiam tratamentos de alto custo), as secretarias de saúde estaduais e municipais precisaram desenvolver novas estruturas para avaliar as necessidades de tratamento médico e administrar recursos financeiros federais e locais para a provisão de medicamentos. Por meio dessa infraestrutura, os cidadãos têm garantido seu acesso aos medicamentos especificados em listas elaboradas por administradores governamentais. ${ }^{7}$ Essas ações delegaram responsabilidades, mas não garantiram financiamentos sustentáveis e a capacidade técnica em instâncias locais. Os medicamentos muitas vezes estão em falta, e as listas de medicamentos novos e de alto custo não são frequentemente atualizadas (Campos, 2007; Homedes, Ugalde, 2005). Também existe um sistema de saúde privado, mas ele não cobre medicamentos, e muitos profissionais da saúde participam dos dois sistemas.

Os ativistas da Aids foram um dos primeiros a conseguir equacionar com êxito o direito constitucional à saúde com o acesso a medicamentos (Scheffer, Salazar, Grou, 2005). Em 1996, quando respostas globais ao HIV/Aids eram mais baseadas em prevenção, o Brasil tornou-se o primeiro país do sul global a assinar uma lei e aprovar uma política de distribuição livre e universal de medicamentos antirretrovirais (ARVs). Nos anos seguintes, o Brasil assistiu à formação de alianças sem precedentes entre ativistas, reformadores governamentais, órgãos multilaterais e a indústria farmacêutica. E foi assim que o país consolidou-se como líder no esforço global para universalizar o acesso ao tratamento da Aids. Uma mudança incremental no conceito de saúde pública foi materializada por meio da política da Aids (Berkman et al., 2005; Galvão, 2002; Okie, 2006; Parker, 2009; Scheffer, Salazar, Grou, 2005). Em termos de serviço, cuidado e demanda, hoje a saúde pública é vista menos como prevenção e assistência básica, e mais como acesso a medicamentos e assistência terceirizada à comunidade - ou seja, a saúde pública tem sido cada vez mais farmaceuticalizada e privatizada (Biehl, 2007).

Atualmente, o acesso ao tratamento é o princípio fundamental do ativismo e intervenções em saúde global (Adams, Novotny, Leslie, 2008; Brown, Cueto, Fee, 2006). Iniciativas públicoprivadas estão em franca expansão, e as empresas farmacêuticas estão se reformulando como empresas voltadas para a saúde global, tornando tratamentos antigos mais amplamente disponíveis e acelerando o acesso a novos tratamentos. Alguns críticos argumentam que parcerias público-privadas e iniciativas filantrópicas podem ser usadas por corporações como uma boa jogada de relações públicas, compensando o escrutínio público da influência política da indústria farmacêutica e a falta de transparência em suas práticas de fixação de preços de medicamentos (Applbaum, 2010; Samsky, 2011). É claro que as empresas também podem usar essas parcerias e iniciativas para se fixar em mercados de países em desenvolvimento, para influenciar políticas de medicamentos nacionais e para aperfeiçoar redes de distribuição de medicamentos. 
Esse é o caso do Brasil. Sob a perspectiva de mercado, ele foi na última década novamente o país do futuro. O governo federal conseguiu conciliar as demandas pela abertura de mercado com uma redução considerável da pobreza: ele afastou-se estrategicamente da regulamentação rigorosa de mercado e, defendendo políticas sociais tão necessárias, consolidou-se como Estado forte, muito além de um governo neoliberal com envolvimento mínimo. Em 2009, o PIB do Brasil era de US\$1,796 trilhão, e seu PIB per capita era de US\$10.427, ocupando a $103^{a}$ posição no mundo (Banco Mundial, 2009). Em 2004, cerca de $20 \%$ da população vivia abaixo da linha de pobreza, número que caiu para 7\% em 2009. A desigualdade de renda no Brasil (conforme medido pelo coeficiente Gini) é uma das maiores do mundo, mas, segundo o Banco Mundial (2009), ela tem diminuído em virtude de "inflação baixa, crescimento econômico constante, programas sociais bem focados e uma política de aumentos reais do salário mínimo". A atual crise do país põe em xeque a sustentabilidade de avanços socioeconômicos recentes e também nos leva a questionar a veracidade desses dados e sua função política (Nobre, 2013). O recente clamor popular contra a corrupção põe em destaque a política eleitoreira de um governo que diz operar sob o verniz da transparência e da equidade social (Romero, 2015).

Em todo caso, fato é que hoje, no campo da saúde, os mais variados atores - associações de pacientes, defensores da indústria e médicos do sistema público de saúde e particulares expressam um claro interesse em tornar a medicina de alta tecnologia acessível a todos. Nesse processo, o país está se tornando uma plataforma rentável para a medicina global. Cerca de metade da população adulta toma remédios diariamente (Carvalho et al., 2005). É aí que o Estado entra em cena: no acesso a medicamentos.

Em uma conversa sobre a fixação desigual de preços de medicamentos no mundo inteiro, um executivo farmacêutico sugeriu que sua empresa estava se adaptando aos contextos de direitos humanos e justiça social que haviam, no passado recente, politizado com êxito o acesso a tratamentos e à saúde. Referindo-se, por exemplo, à constante luta pelo acesso contínuo a terapias antirretrovirais avançadas no Brasil, ele disse sem rodeios que sua empresa havia cooptado a função ativista. Para que o governo atue de maneira adequada, ele sugeriu: "Você não precisa de ativistas. Basta comprar nossos medicamentos para economizar dinheiro". Todos nós sabemos, no entanto, que o preço de medicamentos no Brasil é 1,9 vez o preço na Suécia e 13,1 vezes o índice mundial (Nóbrega et al., 2007).

O Brasil agora vivencia os tipos de problemas e conflitos que outros países de renda média e baixa começam a enfrentar ao tratar a Aids. Aqui, os ARVs de primeira linha são de baixo custo, mas um número crescente de pacientes começa novos, e mais caros, regimes medicamentosos, devido à resistência ao medicamento ou porque os novos medicamentos patenteados apresentam menos efeitos colaterais. Entre 2004 e 2005, o custo do tratamento de um único paciente com Aids subiu de US\$1.220 a US\$2.577, e o custo total das terapias de tratamento da Aids mais que dobrou de 193 milhões para 414 milhões de dólares (Nunn et al., 2009). Em 2009, 32 diferentes medicamentos foram disponibilizados no programa brasileiro de tratamento da infecção por HIV/Aids: 59\% deles (19 medicamentos) foram importados, e seu custo comprometeu $72 \%$ do valor total gasto.

Os medicamentos de alto custo adquiridos pelo Estado constituem um enorme mercado no Brasil - que cresceu de US\$208 milhões, em 2004, para US\$377 milhões, em 2005. Em 
2002, o Ministério da Saúde gastou mais de um bilhão de dólares em medicamentos essenciais e de alto custo. Em 2007, gastou em torno de cinco bilhões. ${ }^{8}$ As despesas com medicamentos aumentaram 252\% entre 2002 e 2007 (Vieira, 2009).

O modelo pautado por direitos e ações judiciais que serviu de base à reivindicação do acesso ao tratamento da Aids foi adotado por outros grupos de pacientes, que agora também lutam na justiça pelo direito a medicamentos. Pessoas de todas as classes sociais estão se mobilizando para ter acesso contínuo a medicamentos cobertos por programas governamentais, mas que não estão disponíveis a essas pessoas, ou a tratamentos especializados ainda não incluídos nas listas oficiais (por exemplo, tratamentos para desordens predominantes, incomuns e raras, como a diabetes, o transtorno bipolar, a asma, a hepatite $\mathrm{C}$ e desordens genéticas raras como a MPS).

Ana Márcia Messeder e colaboradores (2005) descreveram esse fenômeno médico-judicial no estado do Rio de Janeiro. Os autores identificaram um total de 2.733 ações judiciais na área médica movidas entre janeiro de 1991 e dezembro de 2002, e analisaram uma amostra representativa de 389 delas. A maioria das ações foi iniciada por defensores públicos ou por advogados pro bono de organizações não governamentais (ONGs) ou universidades, e apenas $16 \%$ das ações eram de pacientes tratados fora do SUS. Até 1998, os requerentes exigiam quase exclusivamente medicamentos para tratamento do HIV/Aids.

A partir de 1999, com dois anos de aplicação da política universal de tratamento da Aids, houve uma diversificação significativa nos tipos de tratamentos e patologias que constituíam os sujeitos do litígio sobre direito à saúde. As doenças agora incluíam diabetes, câncer e outras patologias além de HIV/Aids. Como cada vez mais pacientes adotaram o discurso dos direitos e as práticas jurídicas iniciadas pelos ativistas da Aids, o número de ações judiciais aumentou consideravelmente. Em 1995, apenas quatro ações judiciais foram ajuizadas contra o estado do Rio de Janeiro. Em 1997, esse número aumentou para 314 e, em 2002, chegou a 1.144. Em seu estudo, Messeder e colaboradores (2005, p.532) mostram que pacientes estavam exercendo grande habilidade organizacional e de lobby como forma de garantir seus direitos, mas defensores públicos e juízes não tinham clareza a respeito da divisão da responsabilidade farmacêutica entre os diversos níveis administrativos. Na verdade, eles pareciam "desconsiderar o uso racional de medicamentos e os possíveis danos causados por prescrições erradas e uso inadequado" (p.533).

Esses pacientes-litigantes brasileiros mostravam ter conhecimento e habilidade que não eram comuns a sua classe, e estavam operando dentro do Estado, desafiando as administrações de saúde pública a cumprirem seus mandatos. Embora o debate público sobre a judicialização tenda a focar nas demandas por medicamentos experimentais e de alto custo, dois estudos importantes do litígio sobre direito à saúde (do estado do Rio de Janeiro - Pepe et al., 2010; e do município de São Paulo - Vieira, Zucchi, 2007) mostram que, na maioria dos casos, os remédios solicitados já faziam parte das listas oficiais de medicamentos e que cerca de 3/4 dos medicamentos solicitados não constantes nas listas tinham equivalentes genéricos que devereiam estar disponíveis ao público. Esse fenômeno novo - requerer medicamentos que já constam em listas oficiais - pode ser um indicador de que as administrações municipais (os supostos provedores) e as secretarias de saúde estaduais (os supostos cofinanciadores) não conseguiram cumprir seus deveres em relação à saúde pública. 
Apesar de as reivindicações de acesso a medicamentos terem ido além de HIV/Aids e de o litígio sobre direito à saúde ter se tornado um caminho alternativo para acessar o sistema de saúde no Brasil, uma sentença do Supremo Tribunal Federal, em 2000, referente ao acesso de um paciente a um novo medicamento antirretroviral ainda constitui o precedente para a intervenção judicial em tribunais estaduais e federais. Em sua sentença, o ministro Celso de Mello entende o programa de assistência farmacêutica no tratamento da Aids como a concretização do dever constitucional do governo de implementar políticas que garantam a saúde da população. Como a representação concreta da necessidade de "normas programáticas", o programa da Aids adquire um valor judicial inerente na sentença de Mello. Assim que os cidadãos recebem os medicamentos de que carecem, a responsabilidade legal do governo por implementar normas programáticas que garantam a saúde termina, deixando, assim, de ser "uma promessa constitucional inconsequente". Segundo essa interpretação, a garantia imediata do direito à saúde por meio de fármacos contorna questões sobre as limitações da política e de recursos, bem como a base de evidências da eficácia de novos medicamentos.

Os atores e as instituições que atuam na saúde pública ao redor do mundo, no momento, buscam uma forma de garantir o direito humano à saúde e de cumprir as promessas de aumento do acesso a tratamentos lidando ao mesmo tempo, com os debates recorrentes sobre prevenção versus tratamento e as limitações dos sistemas de cuidado. Com o aumento da demanda e da importância da judicialização do direito à saúde no Brasil, isso marca o início de um novo capítulo na construção e no gerenciamento do sistema de saúde universal no país, bem como do crescente setor farmacêutico de sua economia - o oitavo maior mercado farmacêutico do mundo (com valor de mercado total estimado em trinta bilhões de dólares em 2012, segundo o Sindicato das Indústrias Farmacêuticas do Estado de São Paulo). A resposta do Brasil à judicialização do direito à saúde é uma prova decisiva para os demais países emergentes em que está crescendo o acesso a medicamentos.

\section{Litígio sobre direito à saúde}

O processo legal da pequena Rita, assim como o dos outros pacientes submetidos à terapia de reposição enzimática no Hospital Universitário, permaneciam sem solução. Segundo o doutor Moura, advogado que representava várias dessas famílias, já havia "meio metro" de documentação reunida. Moura considera o litígio como a única saída, porque "o Estado não cumpre seu papel. A saúde é dever do Estado e direito do paciente". Ele insiste que, na maioria dos casos, as sentenças iniciais são favoráveis aos pacientes. Para ele, as terapias genéticas são um novo limiar na judicialização do direito à saúde. Por quê? "Porque estes são medicamentos com um custo 'um pouco' elevado".

Os estados brasileiros veem o número de ações judiciais bem-sucedidas nos tribunais, chegando a dezenas de milhares, um processo que tem redefinido as funções e responsabilidades do Estado, alterando as práticas administrativas e excedendo os orçamentos da saúde. Com uma população de 11 milhões, o estado do Rio Grande do Sul enfrenta um dos índices mais elevados de ações judiciais relativas à saúde no país (Hoffmann, Bentes, 2008). Em 2009 apenas, mais de 12 mil ações foram movidas no estado em busca do acesso a medicamentos, 
um aumento surpreendente em relação às 1.126 ações de 2002. Em 2008, o estado gastou US\$30,2 milhões em medicamentos por mandados judiciais, uma despesa que representou $22 \%$ das despesas do estado com medicamentos naquele ano (Biehl et al., 2009).

Vejamos o caso de Lizete, que está movendo uma ação contra o Estado para obter medicamentos para tratar de sua hipertensão pulmonar. Ela tem 50 anos de idade e vive com seu marido, motorista de táxi, na periferia de Porto Alegre. Lizete descobriu que era portadora do vírus HIV em 2002. Diferente das terapias de Aids, que ela recebe gratuitamente no posto de saúde local, o medicamento de que ela precisa com maior urgência não é oferecido pelo sistema de saúde público e custaria em torno de US\$1.300 por mês. A conselho de seu médico, Lizete procurou a defensoria pública, onde ela estava qualificada para receber representação legal gratuita, e entrou com uma ação contra o Estado. Inicialmente, ela perdeu a ação. Mas, posteriormente, ganhou o recurso. Embora um juiz distrital tenha ordenado que o Estado começasse imediatamente a provisão do medicamento, quando ela foi entrevistada em agosto de 2009, vários meses haviam se passado e Lizete ainda não tinha recebido o medicamento. Ela esperava se recuperar para poder voltar ao trabalho e cuidar melhor de seu filho adotivo de 11 anos.

Várias pesquisas têm sugerido que o litígio sobre direito ao tratamento, em sua maior parte, é uma prática dos indivíduos que dispõem de mais recursos financeiros (Chieffi, Barata, 2009; Da Silva, Terrazas, 2011; Vieira, Zucchi, 2007) e que pacientes de baixa renda tendem a processar por medicamentos de baixo custo, enquanto pacientes de alta renda tendem a processar por medicamentos muito caros (Da Silva, Terrazas, 2011, p.12). Em contraste, uma análise que fizemos das informações coletadas de 1.080 ações judiciais contra o estado do Rio Grande do Sul ${ }^{9}$ para obter medicamentos (entre 2002 e 2009) sugere que os pacientes que procuram tratamentos recorrendo aos tribunais são, em sua maioria, pessoas pobres que estão fora do mercado de trabalho e dependem do sistema público para obter tratamento médico e representação jurídica (Biehl et al., 2012). Entre os requerentes que relataram sua situação de emprego, mais da metade estava aposentada e cerca de 1/5 estava desempregado. Entre aqueles que relataram sua renda, mais da metade ganhava menos de um salário mínimo por mês (em torno de trezentos dólares) e contava com os serviços jurídicos gratuitos dos defensores públicos.

Em torno de 2/3 dos medicamentos solicitados no nosso banco de dados já constavam das listas oficiais de medicamentos. Cerca de 1/4 das ações judiciais eram exclusivamente para acesso a medicamentos de alto custo das listas, e medicamentos básicos de baixo custo eram solicitados com frequência junto com outros medicamentos. Os medicamentos fora das listas solicitados pelos requerentes também costumavam ser de baixo custo, e muitos já estavam disponíveis no mercado há muito tempo. Isso sugere que os programas do governo de distribuição de medicamentos não estão cumprindo sua função de expandir o acesso e racionalizar o uso (Decit, 2006; Guimarães, 2004).

Somado a isso, juízes distritais e de tribunais de esferas superiores concedem acesso quase universal a todos os medicamentos solicitados, reconhecendo que sua provisão está em conformidade com o direito constitucional à saúde no Brasil. Por exemplo, em quase todas as 1.080 ações judiciais examinadas, os juízes distritais concederam aos requerentes uma injunção imediata para o acesso aos medicamentos; nos casos em que a sentença inicial era favorável à provisão de medicamentos, a instância superior do Estado quase sempre sustentou a decisão. 
Segundo o acadêmico da área jurídica David Fidler (2008), os desenvolvimentos na jurisprudência da saúde "produziram uma anarquia de código aberto e uma relação mais elástica entre poder e ideias na política global". Nessa relação elástica, "as mudanças nas capacidades materiais de atores estatais e não estatais, e as mudanças no mundo das ideias, têm maior impacto umas sobre as outras do que no sistema fechado, centrado no estado que prevaleceu durante a Guerra Fria" (p.410). Fidler reconhece uma "importância maior da lei nos esforços da saúde pública dentro de e entre países" (Fidler, 2008, p.394; ver também Fidler, 2007).

Os antropólogos John e Jean Comaroff têm presenciado a chamada "judicialização da política" na África do Sul pós-apartheid e como isso afetou a mobilização social, especialmente no campo de HIV/Aids. Eles alegam que as lutas de classes "parecem ter se metamorfoseado em ações de classe. Cidadãos, sujeitos, governos e corporações enfrentam-se em litígios uns contra os outros, muitas vezes na confluência de normas de responsabilidade civil, lei dos direitos humanos e lei penal, em um caleidoscópio de coalizões e clivagens, em contínua mutação" (Comaroff, Comaroff, 2006, p.26; ver também Vianna, Burgos, 2005; Yamin, Parra-Vera, 2010).

O litígio sobre direito à saúde também manifesta uma "anarquia de código aberto" produtiva (Fidler, 2008) em macro e microníveis no Brasil. Entrevistas que realizamos com juízes, advogados e servidores da saúde pública revelaram visões divergentes e conflitantes sobre o percurso do litígio que, conforme temos sugerido, tornou-se rota alternativa para o acesso ao cuidado e à saúde. Muitos juízes que trabalham em casos sobre direito à saúde sentem que estão cumprindo sua função constitutional e respondendo à incapacidade de o Estado oferecer medicamentos necessários, e que essas ondas de ações judiciais são um marco na democratização de uma cultura de direitos no país. Questiona-se, entretanto, a real possibilidade de essa meta ser atingida por meio de reivindicações individuais. Fato é que juízes empregam lógicas idiossincráticas e criam seus próprios padrões ao adjudicar casos sobre direito à saúde. Eles citam o "risco de morte" e o "direito à vida" e baseiam grande parte de suas sentenças na jurisprudência (como a do ministro Mello, mencionada anteriormente) e em experiências pessoais - contam histórias trágicas em que consideram que a provisão de tratamento teria feito diferença.

Os administradores públicos, por outro lado, argumentam que o Judiciário está exorbitando sua função e que a judicialização desvia orçamentos e aumenta as desigualdades no acesso a serviços de saúde. Alguns reconhecem, no entanto, que a pressão jurídica melhorou a distribuição de alguns medicamentos. Enquanto isso, escritórios de advocacia especializados em ações para obter o direito à saúde, como o do doutor Moura, multiplicaram-se, e as autoridades locais estão capitalizando politicamente os casos submetidos a tribunais, usandoos para ganhar a atenção da mídia e o apoio popular. Muitos pacientes são de fato pobres e são representados por advogados da defensoria pública. Os defensores públicos entrevistados consideram seu trabalho um modo de garantir a responsabilidade do governo; eles também buscam maior visibilidade da defensoria e importância política nas instituições estaduais. As associações de pacientes têm papel altamente contestado. As autoridades alegam que, pelo menos algumas, são financiadas por empresas farmacêuticas ávidas por vender ao governo os medicamentos de alto custo, cuja eficácia pode ser questionável e a prescrição generalizada não garantida. 
A judicialização da saúde passou a ser de fato uma "infraestrutura paralela", em que uma míriade de atores, setores e alçadas entram em contato, confrontam-se e adotam missões de resgate particulares. Em abril de 2009, o Supremo Tribunal Federal realizou uma rara audiência pública para examinar os desafios prementes apresentados pelo litígio do direito à saúde. ${ }^{10}$ Autoridades da saúde pública, advogados, médicos, ativistas e acadêmicos apresentaram seus depoimentos diante do Tribunal, oferecendo uma variedade de pontos de vista e recomendações sobre como responder à enorme demanda judicial por tecnologias médicas. Um resultado imediato foi a atualização, há muito atrasada, das listas para medicamentos especializados de alto custo. O Conselho Nacional de Justiça também emitiu uma série de recomendações aos juízes locais, solicitando prestar mais atenção a evidências científicas e procurar "mais eficácia" na decisões de casos relativos à saúde. ${ }^{11}$

Se o acesso a terapias da Aids era a prova de fogo do direito à saúde na década de 1990, agora é o acesso a terapias genéticas. Uma das decisões judiciais mais importantes do início desta década envolvia a solicitação de um medicamento para tratar uma doença genética. Esse tratamento não era recomendado pelas diretrizes terapêuticas do Ministério da Saúde e não estava disponível ao público. Em março de 2010, o Supremo Tribunal Federal rejeitou o argumento de que o Estado não era responsável e tomou uma decisão favorável à provisão da terapia de alto custo. Nessa sentença, o ministro Gilmar Mendes afirmou que, após a confirmação médica da doença e a indicação do tratamento, as "diretrizes terapêuticas do Ministério da Saúde podem ser questionadas". Além disso, "o Estado precisa prover recursos, não apenas para apoiar e financiar a provisão de um sistema universal de saúde para os cidadãos, mas também precisa oferecer recursos variáveis para atender às necessidades de cada cidadão individualmente".

Há um fervoroso debate nos tribunais brasileiros acerca do dever positivo imposto ao Estado pelo direito constitucional à saúde e até que ponto os tribunais devem forçar esse direito. O país, contudo, ainda carece de um debate público substancial no tocante ao significado e ao objeto do direito à saúde à luz dos novos avanços médicos. Embora um "direito a medicamentos" esteja se consolidando no Brasil (consolidando, de uma forma mais ampla, a farmaceuticalização da saúde), os vários braços do governo ainda precisam desenvolver avaliações sólidas da tecnologia em saúde. Somadas a isso, são necessárias medidas regulatórias mais audaciosas na fixação de preços de medicamentos, juntamente com reconsideração das responsabilidades dos planos de seguro saúde privados na cobertura de custos com medicamentos (que no momento não existe). Deve-se atentar também para os aspectos mais abrangentes do direito à saúde, incluindo intervenções infraestruturais e com respeito aos determinantes sociais da saúde, como educação, água potável, saneamento, controle de vetores, poluição do ar e prevenção da violência. Enquanto isso, pacientescidadãos-consumidores, de difícil definição, valem-se da linguagem e da jurisprudência dos direitos humanos, e fazem com que os governos funcionem para eles, enquanto navegam os imprevistos do mercado e da sobrevivência.

Prestar atenção às trajetórias e formas dos litígios sobre direito à saúde é penetrar um campo político-econômico-experiencial muito controverso. Aqui notamos que a penetração dos princípios de mercado na prestação de serviços de saúde está inexplicavelmente alinhada à figura do sujeito legal. O sujeito econômico que toma a decisão racional (necessariamente 
um consumidor de tecnologia) também é o sujeito de direitos jurídicos. Essa posição de sujeito duplo complica a teoria de biopoder de Michel Foucault $(1980,2007)$ - a forma como a vida natural tornou-se um objeto de políticas modernas. Na judicialização, não encontramos um modelo biopolítico vertical de governança em que o bem-estar da população e a normalização individual sejam objetos de conhecimento e controle, mas sim uma contestação sobre a utilidade do governo por vários stakeholders privados e públicos. Há uma razão econômica por trás da racionalidade governamental. ${ }^{12} \mathrm{O}$ que está em jogo aqui são as formas pelas quais o governo (na qualidade de regulador, comprador e distribuidor de medicamentos) facilita uma relação mais "direta" de sujeitos atomizados de direitos " $\mathrm{e}$ " interesses com o mercado biomédico, sob a forma de acesso à tecnologia, junto com a criação contínua de horizontes comerciais.

\section{Cidadania e experimentalidade}

A doutora Maria contou-nos que a Rita tem um "caso grave" de MPS. Sua mãe Ilse acrescentou que "até os 4 anos de idade, ela andava. Chegou a frequentar o jardim de infância, mas agora seu corpo inteiro está debilitado. Os órgãos, o fígado e o baço aumentaram, e ela também sofre com problemas respiratórios". Ilse insiste que a Rita melhorou durante os ensaios clínicos, mas ela também sabia que a enzima não poderia "deter os danos neurológicos". Posteriormente, a doutora Maria contou-nos que acreditava que, no caso de Rita, os danos neurológicos eram tamanhos, que a reposição enzimática não seria eficaz. Ainda assim, todos os pais com quem conversamos sugeriram que não obter esse tratamento (cujo acesso eles teriam que renovar periodicamente nos tribunais) seria inconcebível ou equivalente a dar um atestado de morte a seus filhos.

O doutor Daniel Muller, que coordena testes de MPS no Hospital Universitário, não vê os tratamentos de alta tecnologia para MPS como varinhas de condão. Ele disse: "Podem até estabilizar a doença ou talvez levar a pequenas melhoras". Muller também destacou a necessidade de uma abordagem genética voltada para a comunidade: "Temos ferramentas para entrar na comunidade e trabalhar preventivamente em nível de exame pré-natal e primeiros cuidados da criança". Porém, apesar de novos diagnósticos genéticos estarem começando a circular no sistema de saúde pública, "médicos não podem oferecer a opção da interrupção da gravidez", ele acrescentou, "devido à legislação antiaborto deste país predominantemente católico".

O imperativo terapêutico manifestado pelas famílias com as quais conversamos - "faríamos qualquer coisa e iríamos a qualquer lugar para obter o tratamento" - está incorporado a um contexto médico-jurídico-religioso complexo. Nas palavras do doutor Muller: um "problema continental conservador". Para complicar as coisas ainda mais, os laços afetivo das famílias se tornaram catalisadores da aceitação popular, e problemática, de tratamentos de alta tecnologia. De acordo com Muller, muitas famílias tomam "decisões mais emocionais que racionais": "Embora existam escalas clínicas para fazer a distinção entre as formas graves, intermediárias ou brandas da doença que podem nos ajudar a decidir quais casos devem ou não ser tratados ... hoje, com a judicialização, o tratamento depende da família e do entendimento do juiz. Se não damos uma receita médica às famílias, elas podem procurar outro médico". 
Os ensaios clínicos iniciais com a MPS, dos quais Rita participou, testaram a eficácia da reposição enzimática em crianças mais velhas e em jovens adultos. Agora que ela foi aprovada e pode ser encontrada no mercado, novos experimentos estão testando seu uso seguro em crianças mais novas. O doutor Muller contou-nos que o estudo coordenado por ele no Hospital Universitário atraiu 12 novas famílias do Brasil inteiro e também do Chile e da Bolívia.

É difícil discernir se esses ensaios clínicos são para o bem público ou simplesmente um mecanismo explorador (Petryna, 2009). As empresas farmacêuticas estão recrutando cada vez mais centros especializados de tratamento público em países em desenvolvimento, como o serviço de genética no Hospital Universitário, para realizar experimentos. Esses centros têm equipes altamente qualificadas e a capacidade de recrutar pools de pacientes específicos. Por exemplo, há cerca de seiscentos pacientes diagnosticados com MPS 6 (um dos subtipos da mucopolissacaridose) no mundo inteiro, e 1/4 deles vive no Brasil. Com o desdobramento de ensaios clínicos e a produção de evidência, os experimentos passam a ser ferramentas poderosas de marketing, pois vários atores lutam para tornar o tratamento padrão por meio de um protocolo, e reembolsável por empresas de seguro saúde (nos EUA) ou pelo governo (em países como o judicializado Brasil).

Ilse afirmou que cuidar de Rita é "meu trabalho, em tempo integral". Seu segundo marido, o pai de Rita, é quem sustenta a família. Após descobrir a condição da menina e dispostos a evitar "os 75\% de chance de nascer outra criança com MPS", o casal optou por adotar um menino. Ele traz "alegria à casa", disse Ilse. Os pais desejam que os tribunais garantam o tratamento de Rita "pela vida inteira". A mãe prosseguiu: "Ela não ficará curada da MPS. Não existe cura. Mas ela precisa da enzima". Para Ilse, o imperativo terapêutico não é um incentivo para a cura, mas um esforço para manter Rita viva. Indiscutivelmente, aqui a biopolítica do Estado está vinculada ao acesso à tecnologia, e "fazer viver e deixar morrer" (como diria Michel Foucault) tornou-se um caso familiar. "O Estado deve oferecer isso a ela. É estressante ter uma criança doente e precisar lutar na Justiça para que ela obtenha o medicamento ao qual tem direito. Esse é um direito da Rita como cidadã brasileira. Mas estamos sempre lutando junto a juízes, promotores públicos... isso é tão cansativo. Este é o meu trabalho, dia e noite".

Mirta e seus dois filhos com MPS são da cidade rural de Fronteira. Sua primeira filha "também teve a doença, mas faleceu aos 3 anos de idade. Hoje ela estaria com 22 anos. Não havia tratamento na época". Quando perguntamos a idade às crianças, Jessica balbuciou um número e sua mãe disse "mais alto". Ela respondeu: "Dez". Pedro tinha 8 anos. Suas infusões haviam terminado e eles estavam assistindo a um desenho animado na TV.

"É uma batalha", disse Mirta, referindo-se ao fato de que sua família precisou atuar como um sujeito duplo de direitos e interesses neste complexo terapêutico Estado-mercado. "Toda semana saímos de Fronteira à 1 h30 da manhã. A prefeitura oferece o transporte de van. Chegamos aqui às 6h30 e, quando a infusão termina, voltamos para casa". O marido de Mirta gerencia a coleta de lixo da cidade. "A Jessica anda, mas o Pedro consegue andar muito pouco. Eles vão à escola no turno da tarde". Quando perguntamos como faz para se sustentar, Mirta disse simplesmente: "Cuido deles". Sabíamos que essas crianças estavam enfrentando dificuldades para ter acesso à terapia de reposição de enzima. Mirta disse: "Sim, precisamos entrar com ações na Justiça o tempo todo". 
Durante muitos anos, Jessica e Pedro vinham ao serviço genético para exames e tratamentos paliativos. Mirta lamenta que, quando foi lançado um estudo para testar a enzima, seus filhos "não atendiam ao critério de ter 6 anos ou mais". Ela interpretou essa exclusão em termos constitucionais: "Eles não tiveram 'o direito a ser pesquisados'”. Excluída, a família, no entanto, permaneceu atenta ao estudo da MPS. Quando ele foi publicado e a terapia foi aprovada pela Anvisa e disponibilizada no Brasil, "os médicos nos procuraram e perguntaram se gostaríamos de entrar na Justiça para tentar obter o tratamento. É claro que aceitamos. Os médicos e a associação da MPS estão sempre em contato conosco".

Não existe uma população biopolítica predeterminada à qual pertençam esses sujeitos médicos atomizados de direitos. E em seus esforços particulares em se tornar tais sujeitos, crianças e guardiões precisam contar com coletividades temporárias, como as associações de pacientes que surgem na interseção da demanda paciente/família, o marketing farmacêutico e o ativismo jurídico. Mirta é grata ao advogado que "a associação da MPS contratou para nós", mas ela não consegue lembrar seu nome ou os termos em que os casos de Jessica e Pedro foram defendidos perante os juízes que emitiram parecer com base nas reivindicações. Ela também não tinha uma noção clara de como atuar em sua posição de sujeito jurídico roteirizado, e ela sofria com as constantes incertezas e brigas judiciais relativas à renovação do acesso à terapia de reposição enzimática. "Jessica obteve o tratamento por noventa dias, e Pedro, por quarenta. Os casos nunca são analisados pelo mesmo juiz".

\section{O acesso à tecnologia e a saúde privatizada}

A questão da continuidade no tratamento tem grande peso na decisão dos médicos que submetem seus pacientes a ensaios clínicos ou que prescrevem essas terapias genéticas. Muitos dos médicos entrevistados mencionaram que, ao término dos estudos, os patrocinadores dos ensaios às vezes continuam a fornecer o medicamento por algum tempo, como parte de um programa de acesso estendido ou de uso compassivo. "Mas isso fica a critério da empresa". A doutora Maria destaca que a constituição biológica dessas crianças é prejudicada seriamente pela descontinuidade do tratamento: "Às vezes, eles recebem os medicamentos, outras vezes, não". Pedro e Jessica sofrem com a "total falta de consistência" no acesso à terapia.

Assim como a biologia dessas crianças está precariamente atrelada a novas biotecnologias, as sentenças e liminares judiciais também desencadeiam seus próprios tipos de riscos. A doutora Maria afirmou que "os pacientes ficam um período sem o tratamento até a decisão da liminar judicial". Os médicos oferecem provas para as reivindicações legais dos pacientes por tratamento, mas os tribunais se tornam campos de batalha de veredicto-falsificação porque a Procuradoria Geral da República criou uma força-tarefa de especialistas em medicina baseada em evidência que apoiam ou desqualificam as reivindicações de acesso a tratamentos e sua eficácia.

Os conflitos em torno de evidências nos tribunais acabam gerando mais um conjunto de problemas médicos. Segundo a doutora Maria, "é pior começar um tratamento e precisar interrompê-lo que nunca iniciá-lo. Quando o tratamento é interrompido e, depois, retomado por determinação de uma nova sentença ou injunção, os pacientes quase sempre têm uma reação adversa à terapia. A proteína da terapia é estranha aos seus corpos. Em relatórios 
médicos apresentados como parte de ações judiciais, procuramos defender a noção de que o tratamento não deve ser interrompido, mas sabemos que esse argumento nem sempre funciona".

Como a aclamada equação econômica de que "mais tecnologia equivale a melhores resultados na saúde" (Cutler, McClellan, 2001; Cutler, Deaton, Lleras-Muney, 2006) pode ser compatível com a judicialização da saúde? Um grande desafio enfrentado por clínicos como a doutora Maria e seus colegas é encontrar uma forma de avaliar se a enzima está de fato melhorando a condição do paciente. Até mesmo no estágio de pós-comercialização da terapia, os pacientes permanecem em uma espécie de experimentalidade. "Qual é o real benefício do tratamento para o paciente? Eles conviveram com a doença por período prolongado, em torno de 8 a 9 anos, e quase não receberam tratamento em todos esses anos. Sabemos que a enzima melhora a função pulmonar. Mas quando se trata de outros marcadores, precisamos de mais tempo para realmente avaliar seu efeito". A judicialização do acesso farmacêutico, caso a caso, parece ter aberto uma frágil brecha adicional entre tratamento e pesquisa. Essa fragilidade pode muito bem ser substituída por protocolos padronizados e novos regimes no futuro. Mas nos perguntamos até que ponto os pais estão conscientes do caráter experimental (Petryna, 2009) do que está acontecendo nos corpos de seus filhos-litigantes. Como podemos facilitar um debate mais esclarecedor com a sociedade sobre as incertezas vividas da ciência, da eficácia e dos reais custos de avanços terapêuticos?

Os pais na unidade de genética do hospital desenvolveram suas próprias medidas informais da eficácia das terapias de reposição enzimática. Mirta, por exemplo, cita que observou um aumento no "nível de atenção e destreza" de seus filhos, bem como detalhes menos perceptíveis, como "maior maciez dos cabelos". Os pais utilizam diversos critérios subjetivos como indicadores dos impactos negativos que a odisseia jurídica tem sobre os filhos: "Sabemos que os constantes litígios não fazem bem para sua saúde. Consigo perceber a diferença", diz Mirta. "Quando a Jessica e o Pedro não recebem o tratamento terapêutico, sua saúde fica comprometida. Eles deveriam recebê-lo continuamente".

À medida que as famílias recorrem a tribunais e apresentam documentação médico-jurídica, seu "abraço biotecnológico" é fortalecido (DelVecchio Good, 2007). Ao mesmo tempo, a eficácia questionável do tratamento de reposição enzimática, que os médicos envolvidos conhecem tão bem, passa a preocupar cada vez menos as famílias. Quando tudo vai bem nesse sistema improvisado de acesso e distribuição de medicamentos, acrescenta Mirta: "O juiz dá o parecer favorável à nossa reivindicação e recebemos o dinheiro para encaminhar ao hospital que, por sua vez, compra a enzima. O tratamento custa 18 mil dólares por mês, o que representa um custo de 36 mil dólares para as duas crianças. É uma quantia alta, não é mesmo?"

Nem mesmo irmãos com a mesma doença, como é o caso de Pedro e Jessica, constituem um coletivo legítimo nesse empreendimento privatizado e maleável de direito à saúde. A doutora Maria destaca a confusão médica e jurídica: “Uma das realidades mais difíceis que enfrentamos é que os juízes dão sentenças diferentes para cada paciente de MPS. Vejamos o caso de dois irmãos em que ambos têm MPS 6. Eles têm diferentes juízes e cada um dá tratamento por diferentes períodos de tempo". Entretanto, segundo o advogado, o doutor Moura, essa é de fato a melhor estratégia jurídica: "Sou contra ações judiciais coletivas. Cada 
paciente de MPS é único e recebe dosagens diferentes, e suas particularidades podem se virar contra eles se o caso for considerado coletivo". Para ele, ações judiciais individuais podem potencialmente contornar os critérios estritos usados em análises de comitês especializados e os recursos de promotores públicos para "adiar cada vez mais o tratamento". Com certeza, o Estado e seus representantes estão colocando em circulação coletivos epistêmicos que surgem de um uso estratégico da medicina baseada em evidências. Esses coletivos virtuais (que ocupam o lugar de uma população com reconhecidas necessidades que já não mais existem) entram em conflito com as posições de sujeito articuladas por pacientes e famílias desesperadas em suas redes temporárias médico-jurídicas e de ativistas.

Pedro e Jessica não tiveram o direito de ser parte de pesquisas clínicas, mas eles tinham o direito constitucional à saúde. Conforme sua mãe explicou: "Eles deveriam obter medicamentos para a vida inteira; assim, não precisaríamos ativar sempre o judiciário, pouco a pouco".

Essa família sentia que sua luta ficaria mais intensa porque a jurisprudência do direito à saúde estava evoluindo de forma imprevisível. A justiça estadual decidiu a favor do governo e considerou um fabricante de medicamentos de MPS responsável pelos custos do tratamento de uma criança que passou por ensaios clínicos. Promotores públicos solicitaram e o tribunal determinou que o fabricante provesse tratamento médico gratuito ao paciente pelo resto da vida, mesmo que isso não estivesse estipulado no consentimento informado. Para justificar a decisão, o Tribunal de Justiça Estadual escreveu que "é inaceitável que o fabricante use seres humanos como 'cobaias' em seus estudos e, depois, abandone essas pessoas, antes de vital importância e agora desamparadas, tentando obter um produto extremamente caro, especialmente quando são observados avanços na saúde e aumenta a expectativa de vida dos pacientes" (Rio Grande do Sul, 2009).

Com a expansão global de mercados biomédicos e de sua incursão em sistemas de saúde pública, observamos significativos deslocamentos institucionais e novas formações de cidadania na interface Estado-mercado. No caso brasileiro, o mercado encontra utilidade no governo como comprador e distribuidor de medicamentos, e em comunidades específicas mobilizadas. Essas comunidades, consideradas segmentos de mercado terapêutico, usam a legislação e a jurisprudência para terem visibilidade junto ao Estado e para fazê-lo atuar de maneira biopolítica. O governo, portanto, orienta-se menos em prol da saúde da população como um meio de alcançar produtividade e controle, e mais em fazer a triagem ou facilitar a relação de sujeitos de interesses (e com direitos) ao mercado biomédico na forma de acesso à tecnologia.

As chances de vida das pessoas e seu bem-estar são sobredeterminados pelo tipo de sujeitos jurídicos e de mercado que elas podem se tornar ao recorrer ao Judiciário e ao governo, bem como aos centros de pesquisa médica e às indústrias da saúde. Precisamos escrutinar as formas de estadismo (nacional e regional) e jurisprudência, assim como as subjetividades políticas que são construídas nesse novo aparato de interesses e direitos que é a judicialização da saúde, se quisermos compreender os campos políticos e as possibilidades de mudança social que se abrem e as dinâmicas de intratabilidade que se consolidam no Brasil de hoje. Sob a perspectiva da judicialização brasileira, vemos que a saúde em tempos de "saúde global" é um trabalho em andamento tocado por sujeitos jurídicos monádicos em relação a mercados terapêuticos, infraestruturas de saúde pública que mal funcionam e coletivos médicos frágeis. 
Este ensaio chamou a atenção para a precariedade das intervenções biopolíticas, mostrando que estão constantemente envolvidas e moldadas por outros imperativos (muitas vezes econômicos). As histórias dos pacientes-litigantes e suas famílias também apontam para o poder de a biotecnologia recriar valores humanos e mundos locais à medida que abre novos espaços de problematização ética, desejo e pertencimento político. É justamente na interseção do imperativo terapêutico, do abraço biotecnológico e da razão do mercado que a intensidade da sobrevivência ganha visibilidade.

\section{NOTAS}

* Este texto foi originalmente publicado em inglês ("Legal remedies: therapeutic markets and the judicialization of the right to health") em BIEHL, João; PETRYNA, Adriana (Ed.). When people come first: critical studies in global health. Princeton: Princeton University Press, 2013. A tradução aqui publicada foi aprovada pelos autores que revisaram partes do original.

${ }^{1}$ Disponível em: http://www.oestrangeiro.net/esquizoanalise/67-o-abecedario-de-gilles-deleuze. Acesso em: 21 fev. 2011.

${ }^{2}$ Uma versão anterior deste capítulo apareceu em Social Research, v.78, v.2, p.359-386, 2011.

${ }^{3}$ Nossos agradecimentos pela pesquisa e assistência editorial de Joseph Amon, Mariana P. Socal, Roberta Grudzinski, Alex Gertner, Joshua Franklin, Jeferson Barbosa, Ramah McKay e Peter Locke. Agradecemos também pelo apoio da Ford Foundation, da Health Grand Initiative Challenges e da Woodrow Wilson School da Princeton University. Exceto nos casos em que indivíduos e instituições optaram por ser identificados, mantivemos seu anonimato, usando pseudônimos.

${ }^{4}$ Ao discutir sobre farmaceuticalização da saúde e judicialização do direito à saúde no Brasil, utilizamos como base o livro de Biehl intitulado Will to live: Aids therapies and the politics of survival (2007) e o livro de Petryna intitulado When experiments travel: clinical trials and the global search for human subjects (2009). Também consultamos um estudo multidisciplinar da judicialização do direito à saúde que está em andamento no sul do Brasil, sob a coordenação de Biehl.

${ }^{5}$ O primeiro tratamento de MPS foi aprovado pela FDA em 2003 (laronidase para a MPS 1), seguido de dois outros medicamentos aprovados em 2005 (galsulfase para a MPS 6) e 2006 (idursulfase para a MPS 2). Esses medicamentos foram aprovados pela Anvisa no Brasil em 2006, 2009 e 2008, respectivamente.

${ }^{6}$ A Lei dos Medicamentos Órfãos (Orphan Drug Act) dos EUA, de 1983, oferece incentivos para o desenvolvimento de medicamentos para tratar doenças raras que afligem "menos de 200.000 pessoas nos EUA" ou "mais de 200.000 pessoas nos EUA, mas para as quais não existe uma expectativa razoável de que o custo do desenvolvimento e da disponibilização de um medicamento nos EUA para essa doença ou condição seja recuperado com as vendas desse medicamento nos EUA". Esses incentivos incluem crédito fiscal para pesquisas clínicas e sete anos de exclusividade de mercado para um medicamento aprovado pela FDA.

${ }^{7}$ O governo federal adquiriu medicamentos de alto custo em circunstâncias excepcionais desde a década de 1970, mas somente em 1993 foi criado um programa oficial, o Programa de Medicamentos Excepcionais, para a aquisição desses medicamentos de alto custo (Brasil, 2010a). O governo federal cedeu a responsabilidade administrativa do programa às secretarias estaduais de saúde, mas sem um mecanismo bem-definido de cofinanciamento. Embora muitos medicamentos tenham sido incluídos nas listas iniciais do programa, apenas alguns foram efetivamente distribuídos à população, devido aos processos de aquisição e distribuição erráticos e irregulares. Em 2002, o Programa de Medicamentos Excepcionais foi estendido para incluir 92 medicamentos e critérios mais precisos foram formulados para informar sua distribuição (Souza, 2002). Finalmente, em 2006, o Ministério da Saúde emitiu um decreto ministerial (portaria GM n.2.577, de 27 de outubro de 2006) detalhando os objetivos e as responsabilidades específicas dos estados e do governo federal em relação ao Programa de Medicamentos Excepcionais (Brasil, 2010a). Atualmente, 110 produtos terapêuticos (incluindo medicamentos, produtos biológicos e fórmulas nutricionais) fazem parte do programa, que agora é chamado de Componente Especializado de Assistência Farmacêutica (Brasil, 2010b).

${ }^{8} \mathrm{Em}$ 2007, quatro medicamentos foram responsáveis por $28 \%$ dos gastos com medicamentos pelo Ministério da Saúde: imiglucerase, epoetina alfa, imunoglobulina humana e interferon alpha-2b.

${ }^{9}$ Ver http://www.princeton.edu/grandchallenges/health/research-highlights/aids/. 
${ }^{10}$ Para obter uma análise detalhada da audição pública, ver: http://www.stf.jus.br/portal/cms/verTexto.asp ?servico=processoAudienciaPublicaSaude.

${ }^{11}$ Em 2010, o Conselho Nacional de Justiça recomendou que juízes sempre verificassem na Comissão Nacional de Ética em Pesquisas (Conep) se o medicamento solicitado fazia "parte dos programas de pesquisa experimental" da indústria farmacêutica e que, nesse caso, os juízes deveriam obrigar essas indústrias a assumir a continuidade do tratamento. (Recomendação n.31, de 30 de março de 2010. DJ-e n.61/2010, em 7 abr. 2010, p.4-6. Disponível em: http://www.cnj.jus.br/index.php?option=com_content\&view=article\&i d=10547:recomendacao-no-31-de-30-de-marco-de-2010\&catid=60:recomendas-do-conseho\&Itemid=515.)

${ }^{12}$ Em suas palestras de 1978-1979 no Collège de France, Foucault (2008, p.32) argumentou que só podemos analisar adequadamente a biopolítica quando compreendemos a razão econômica por trás da razão do governo: "Desde que isso permita a associação de produção, necessidade, fornecimento, demanda, valor, preço etc., por meio da troca, o mercado constitui um local de veridicção, ou seja, um local de veridicçãofalsificação da prática governamental. Consequentemente, o mercado determina que o bom governo não é mais simplesmente um governo que funciona de acordo com a justiça".

\section{REFERÊNCIAS}

ADAMS, Vincanne; NOVOTNY, Thomas; LESLIE, Hannah.

Global health diplomacy. Medical Anthropology, v.27, n.4, p.315-23. 2008.

APPLBAUM, Kalman.

Marketing global health care: the practices of big pharma. In: Panitch, Leo (Ed.). The social register 2010: morbid symptoms: health under capitalism. New York: Monthly Review Press. p.95-115. 2010.

AZEVEDO, Solange.

Remédios nos tribunais. Revista Época, 20 dez. 2007. Disponível em: http://revistaepoca.globo. com/Revista/Epoca/0,,EDG80696-8055-501,00REMEDIOS+NOS+TRIBUNAIS.html. Acesso em: 1 fev. 2016. 20 dez. 2007.

BANCO MUNDIAL.

Brazil, country brief. Disponível em: http:// go.worldbank.org/UW8ODN2SVO. Acesso em: 1 fev. 2016. 2009.

BECK, Michael.

New therapeutic options for lysosomal storage disorders: enzyme replacent, small molecules and gene therapy. Human Genetics, n.121, v.1, p.1-22. 2007.

\section{BERKMAN, Alan et al.}

A critical analysis of the Brazilian response to HIV/AIDS: lessons learned for controlling and mitigating the epidemic in developing countries. American Journal of Public Health, v.95, n.7, p.1162-1172. 2005.

BIEHL, João.

Will to live: Aids therapies and the politics of survival. Princeton: Princeton University Press. 2007.

BIEHL, João et al.

Between the court and the clinic: lawsuits for medicines and the right to health in Brazil. Health and Human Rights, v.14, n.1, p.1-17. 2012.

BIEHL, João et al.

Judicialisation of the right to health in Brazil.

Lancet, v.373, n.9680, p.2182-2184. 2009.

BRASIL.

Ministério da Saúde. Histórico do componente de medicamentos de dispensação excepcional. Disponível em: http://bvsms.saude.gov.br/bvs/ publicacoes/documenta3.pdf. Acesso em: $1 \mathrm{fev}$. 2016. 2010a.

BRASIL.

Ministério da Saúde. Componente especializado da assistência farmacêutica. Disponível em: http://portalsaude.saude.gov.br/index. php?option=com_content\&view=article\&id=116 35\&Itemid=702. Acesso em: 1 fev. 2016. 2010 b.

BRASIL.

Constituição da República Federativa do Brasil de 1988. Disponpível em: http://www.planalto. gov.br/ccivil_03/Constituicao/Constituicao.htm. Acesso em: 1 fev. 2016. 1988.

BROWN, Theodore M; CUETO, Marcos; FEE, Elizabeth.

The World Health Organization and the transition from "international" to "global" public health. American Journal of Public Health, v.96, n.1, p.62-72. 2006.

CAMPOS, Gastão Wagner de Sousa.

O SUS entre a tradição dos sistemas nacionais e o modo liberal-privado para organizar o cuidado à saúde. Ciência e Saúde Coletiva, v.12, supl., p.1865-1874. 2007.

CARVALHO, Marcelo Felga et al.

Utilization of medicines by the Brazilian population, 2003. Cadernos de Saúde Pública, v.21, supl.1, p.100-108. 2005. 
CHIEFFI, Ana Luiza; BARATA, Rita Barradas. Judicialização da política pública de assistência farmacêutica e equidade. Cadernos de Saúde Pública, v.25, n.8, p.1839-1849. 2009.

CLARKE, Lorne A.

The mucopolysaccharidosis: a success of molecular medicine. Expert Reviews in Molecular Medicine, v.10, e1. 2008.

CLARKE, Lorne A.

Mucopolysaccharidosis type I. GeneReviews [Internet], September 21, 2007. Disponível em: http://www.ncbi.nlm.nih.gov/books/NBK1162/. Acesso em: 1 fev. 2016. 21 set. 2007.

COLLUCI, Cláudia.

Triplicam as ações judiciais para obter medicamentos. Folha de S.Paulo, São Paulo, 9 jan. 2009. Disponível em: http://proquest.umi.com/ pdqweb?did $=1653546171 \&$ sid $=2 \&$ Fmt $=3 \&$ clie ntId $=17210 \&$ RQT $=309 \& V$ Name $=P Q D$. Data de acesso: Acesso em: 1 dez. 2012.9 jan. 2009.

COMAROFF, Jean; COMAROFF, John. Law and disorder in the postcolony: an introduction. In: Comaroff, Jean; Comaroff, John (Ed.). Law and disorder in the postcolony. Chicago: University of Chicago Press. p.1-56. 2006.

CUTLER, David M.; DEATON, Angus S.; LLERASMUNEY, Adriana.

The determinants of mortality. Journal of Economic Perspectives, v.20, n.3, p.97-120. 2006.

CUTLER, David M; McCLELLAN, Mark. Is technological change in medicine worth it? Health Affairs, v.20, n.5, p.11-29. 2001.

DA SILVA, Virgílio Afonso; TERRAZAS, Fernanda Vargas.

Claiming the right to health in Brazilian courts: the exclusion of the already excluded? Law and Social Inquiry, v.36, n.4, p.825-853. 2011.

DECIT.

Departamento de Ciência e Tecnologia, Secretaria de Ciência e Tecnologia e Insumos Estratégicos do Ministério da Saúde. Avaliação de tecnologias em saúde: institucionalização das ações no Ministério da Saúde. Revista de Saúde Pública, v.40, n.4, p.743-747. 2006

DELVECCHIO GOOD, Mary-Jo.

The medical imaginary and the biotechnical embrace: subjective experiences of clinical scientists and patients. In: Biehl, João; Good, Byron; Kleinman, Arthur (Ed.). Subjectivity: ethnographic investigations. Berkeley: University of California Press. p.362-380. 2007.

FERRAZ, Octavio Luiz Motta.

The right to health in the courts of Brazil: worsening health inequities? Health and Human Rights: An International Journal, v.11, n.2, p.33-45. 2009.
FIDLER, David.

Global health jurisprudence: a time of reckoning. Georgetown Law Journal, v.96, n.2, p.393-412. 2008.

FIDLER, David.

Architecture amidst anarchy: global health's quest for governance. Global Health Governance, v.1, n.1, p.1-17. Disponível em: http://blogs. shu.edu/ghg/files/2013/02/Fidler_Architectureamidst-Anarchy-Global-Health\%E2\%80\%99sQuest-for-Governance_Spring-2007.pdf. Data de acesso: 2 fev. 2016. 2007.

FOUCAULT, Michel.

The birth of biopolitics: lectures at the Collège de France, 1978-1979. New York: Palgrave Macmillan. 2008.

FOUCAULT, Michel. Security, territory, population: lectures at the College de France, 1977-1978. New York: Picador. 2007.

FOUCAULT, Michel.

The history of sexuality. v.1. New York: Vintage Books. 1980.

GALVÃO, Jane.

Access to antiretroviral drugs in Brazil. Lancet, v.360, n.9348, p.1862-1865. 2002.

GAURI, Varun; BRINKS, Daniel M.

Courting social justice: judicial enforcement of social and economic rights in the developing world. Cambridge: Cambridge University Press. 2008.

GUIMARÃES, Reinaldo.

Bases para uma Política Nacional de Ciência, Tecnologia e Inovação em Saúde. Ciência e Saúde Coletiva, v.9, n.2, p.375-387. 2004.

HOFFMANN, Florian F.; BENTES, Fernando R.N.M.

Accountability for social and economic rights in Brazil. In: Gauri, Varun; Brinks, Daniel M. (Ed.). Courting social justice: judicial enforcement of social and economic rights in the developing world. New York: Cambridge University Press. p.100-145. 2008.

HOMEDES, Núria; UGALDE, Antônio. Why neoliberal health reforms have failed in Latin America. Health Policy, v.71, n.1, p.83-96. 2005.

MESSEDER, Ana Márcia et al. Mandados judiciais como ferramenta para garantia do acesso a medicamentos no setor público: a experiência do Estado do Rio de Janeiro, Brasil. Cadernos de Saúde Pública, v.21, n.2, p.525-534. 2005 . 
NOBRE, Marcos.

Imobilismo em movimento: da abertura democrática ao governo Dilma. São Paulo: Companhia das Letras. 2013.

NOBREGA, Otávio de Tolêdo et al. Retail prices of essential drugs in Brazil: an international comparison. Revista Panamericana de Salud Pública, v.22, n.2, p.118-123. 2007.

NUNN, Amy Stewart et al.

Aids treatment in Brazil: impacts and challenges. Health Affairs, v.28, n.4, p.1103-1113. 2009.

OKIE, Susan.

Fighting HIV: lessons from Brazil. New England Journal of Medicine, v.354, n.19, p.1977-1981. 2006.

PARKER, Richard G.

Civil society, political mobilization, and the impact of HIV scale-up on health systems in Brazil. Journal of Acquired Immune Deficiency Syndromes, v.52, suppl.1, p.S49-S51. 2009.

PEPE, Vera Lúcia Edais et al.

Caracterização de demandas judiciais de fornecimento de medicamentos "essenciais" no Estado do Rio de Janeiro, Brasil. Cadernos de Saúde Pública, v.26, n.3, p.461-471. 2010.

PETRYNA, Adriana.

When experiments travel: clinical trials and the global search for human subjects. Princeton: Princeton University Press. 2009.

RIO GRANDE DO SUL (Estado).

Tribunal de Justiça do Estado do Rio Grande do Sul. Sétima Câmara Cível. Apelação cível n.700031235633. Disponível em: http://www. espacovital.com.br/noticia_complemento_ler. php?id=1690\&noticia_id=17087. Acesso em: 21 fev. 2010. 2009.

ROMERO, Simon.

Scandals in Brazil prompt fears of a return to turmoil. New York Times, 12 ago. 2015.
Disponível em: http://www.nytimes. com/2015/08/13/world/americas/scandals-inbrazil-prompt-fears-of-a-return-to-turmoil.html? r=0. Acesso em: 1 fev. 2016. 12 ago. 2015.

SAMSKY, Ari.

Since we are taking the drugs': labor and value in two international drug donation programs. Journal of Cultural Economy, v.4, n.1, p.27-43. 2011.

SCHEFFER, Mário; SALAZAR, Andrea Lazzarini; GROU, Karina Bozola.

O remédio via justiça: um estudo sobre o acesso a novos medicamentos e exames em HIV/Aids no Brasil por meio de ações judiciais. Brasília: Ministério da Saúde. 2005.

SOUZA, Renilson Rehem de.

O programa de medicamentos excepcionais. In: Picon, Paulo Dornelles; Beltrame, Alberto (Ed.). Protocolos clínicos e diretrizes terapêuticas: medicamentos excepcionais. Brasília: Ministério da Saúde. p.11-12. 2002.

VIANNA, Luiz Werneck; BURGOS, Marcelo Baumann.

Entre princípios e regras: cinco estudos de caso de ação civil pública. Dados, v.48, n.4, p.777-843. 2005.

VIEIRA, Fabiola Sulpino.

Ministry of Health's spending on drugs: program trends from 2002 to 2007. Revista de Saúde Pública, v.43, n.4, p.674-681. 2009.

VIEIRA, Fabiola Sulpino; ZUCCHI, Paola. Distorções causadas pelas ações judiciais à política de medicamentos no Brasil. Revista de Saúde Pública, v.41, n.2, p.214-222. 2007.

YAMIN, Alicia Ely; PARRA-VERA, Oscar. Judicial protection of the right to health in Colombia: from social demands to individual claims to public debates. Hastings International and Comparative Law Review, v.33, n.2, p.101-130. 2010.

\section{$\rightarrow \rightarrow \rightarrow<<<$}

